\title{
Cervical cancer stem cell-associated genes: Prognostic implications in cervical cancer (Review)
}

\author{
JORGE ORGANISTA-NAVA $^{1 *}$, YAZMÍN GÓMEZ-GÓMEZ ${ }^{1 *}$, OLGA LILIA GARIBAY-CERDENARES ${ }^{1,2}$, \\ MARCO ANTONIO LEYVA-VÁZQUEZ ${ }^{1}$ and BERENICE ILLADES-AGUIAR ${ }^{1}$ \\ ${ }^{1}$ Laboratorio de Biomedicina Molecular, Facultad de Ciencias Químico Biológicas, Universidad Autónoma de \\ Guerrero, Chilpancingo, Guerrero 39090; ${ }^{2}$ Consejo Nacional de Ciencia y Tecnología, Mexico City 03940, Mexico
}

Received April 19, 2018; Accepted March 18, 2019

DOI: $10.3892 / \mathrm{ol} .2019 .10307$

\begin{abstract}
Cervical cancer is the fourth most common type of gynecological malignancy to affect females, worldwide. Although high-risk human papillomavirus (HR-HPV) infection is the primary etiologic agent associated with the development of cervical cancer, cancer stem cells (CSCs) also serve a prominent role in the development, metastasis, recurrence and prognosis of the disease. CSCs are a small subpopulation of cells that have the ability to self-renew and are present in the majority of tumors, including cervical cancer. Studies describing the phenotype of cervical CSCs (CCSCs) vary in their definition of the expression pattern of principal biomarkers, including Musashi-1, aldehyde dehydrogenase 1, Oct3/4, Sox2 and CD49f. However, these markers are not observed in all cancers, although several may be present in multiple tumor types. The present review describes the potential biomarkers of CSCs in cervical cancer. These CCSC biomarkers may serve as molecular targets to enhance the efficacy and reduce the side effects associated with chemotherapeutic treatment in HR-HPV-positive cervical cancer.
\end{abstract}

\section{Contents}

1. Introduction

2. HR-HPV-mediated network regulation of CCSCs in cervical cancer

3. Markers of CCSCs as prognostic biomarkers

4. Conclusion

Correspondence to: Professor Berenice Illades-Aguiar or Professor Jorge Organista-Nava, Laboratorio de Biomedicina Molecular, Facultad de Ciencias Químico Biológicas, Universidad Autónoma de Guerrero, Av. Lázaro Cárdenas S/N, Ciudad Universitaria, Chilpancingo, Guerrero 39090, Mexico

E-mail: b.illadesaguiar@gmail.com

E-mail: joorna@gmail.com

${ }^{*}$ Contributed equally

Key words: cervical cancer stem cells, high-risk human papillomavirus, transformation zone, biomarkers

\section{Introduction}

Cervical cancer is the fourth most common type of gynecological malignancy worldwide and has a high mortality rate, particularly in developing countries (1). High-risk human papillomavirus (HR-HPV) has been identified as the primary etiologic agent associated with the development of cervical cancer (2), and the most prevalent HR-HPV types are HPH-16 and HPV-18, accounting for $70 \%$ of cervical cancer cases (3). Currently, the principal challenge in clinical cancer treatment is the resistance of cancer cells to various chemotherapeutic drugs. Cervical cancers harboring HPV are known to exhibit a poor response to treatment with chemotherapeutic agents, and display impaired chemotherapy-induced apoptosis (4).

In the cervical epithelium, the transformation zone (TZ) is a niche of cells with a unique expression profile and embryonic characteristics (5-7). The target cells for HR-HPV infection are cuboidal epithelial cells within the TZ (considered to be the stem cells of the cervical epithelium), which are involved, in malignant transformation (Fig. 1) (6,7).

Cancer stem cells (CSCs) are a small subpopulation of tumor cells with self-renewal capacity, which maintain tumor growth and cell differentiation. Cell surface markers and transcription factors, including CD44, aldehyde dehydrogenase 1 (ALDH1), Nanog and Oct4, have been used to isolate and enrich CSC populations from different tumors, including cervical cancer (8-10). CSCs contribute to the tumorigenic potential of cancer, including spherogenesis, and resistance to cytotoxic drugs and ionizing radiation (11).

The strategies by which HR-HPV promotes cancer development involve the overexpression of the viral oncoproteins E6 and E7 (12). Recently, it was reported that HPV16 E7 may contribute to the transcriptional upregulation of Oct3/4 and stemness-related genes. HPV16 E7 upregulates Oct3/4, Sox 2, Nanog and fibroblast growth factor 4 expression levels to maintain the self-renewal capacity of CSCs (Fig. 1) (13). Additionally, recurrence in patients with cervical cancer following treatment may be explained by the hierarchy theory of carcinogenesis, which suggests that only CSCs have tumor initiating capacity. It has also been observed that CSCs are associated with tumor metastasis, relapse and chemo/radio-resistance, resulting in unsuccessful treatment 
outcomes $(10,14)$. The present review discusses the role of cervical CSCs as it is currently understood, and how they potentially represent therapeutic targets to improve the treatment of cervical cancer.

\section{HR-HPV-mediated network regulation of CSCs in cervical cancer}

In the $\mathrm{TZ}$ of the cervical epithelium, squamous and columnar cervical neoplasia are initiated by HR-HPV infection, where the virus targets cells that express such surface markers as CD44, CD49f, CK17 and CD133 on the cell membrane; these cells are considered to be the stem cells of the cervical epithelium $(8,10,15-17)$ (Figs. 1 and 2).

During HR-HPV infection of the target cells, viruses bind to receptors on the cell surface, resulting in virus internalization. Viral DNA is released and transported through the endosomes and endo/lysosomes to the cell nucleus $(18,19)$. Subsequently, viral oncoprotein synthesis (including that of E6 and E7) is initiated. E7 and E6 promote the proliferation of infected stem cells by inactivation of the endogenous tumor suppressor proteins retinoblastoma-associated protein $(\mathrm{pRb})$ and $\mathrm{p} 53$, respectively (20). The degradation of $\mathrm{pRb}$ terminates Sox 2 and Oct $3 / 4$ repression (21). Likewise, the degradation of p53 by HR-HPV E6 leads to increased Nanog expression levels (22).

HR-HPV oncoproteins increase the expression of stemness-related genes (Oct3/4, Nanog, Sox 2 and Notch3) and promote cell self-renewal $(13,23,24)$. It has also been observed that overexpression of stemness-related genes promotes the formation of tumors, inhibits cancer cell apoptosis, cell migration, sphere formation and chemoresistance (25-29). These findings suggest that HR-HPV promotes self-renewal through the upregulation of Oct $3 / 4$, Sox 2 and Nanog expression to maintain the cervical cancer stem cell (CCSC) population in cervical tumors (Fig. 2). The CCSC population is frequently resistant to chemotherapy, and stemness-related genes regulate numerous other genes; this includes certain ATP-binding cassette (ABC) transporters, which are known to be associated with drug resistance. Increased expression levels of Oct3/4, Nanog, Sox 2 and Notch 3 are reported to promote drug resistance in CSCs. Additionally, the expression of ABC transporters, ALDH1 and Musashi-1 (MSI1) is increased in cells with high expression levels of Oct3/4-Nanog, Sox 2 and Notch3, respectively (29-32). These data indicate that stemness-related genes (Oct3/4, Nanog, Sox2, Notch3) are associated with the expression of ABC, ALDH1 and MSI1, which may promote the clonogenicity, proliferation, invasiveness and chemoresistance of CSCs (Fig. 2).

\section{Markers of CCSCs as prognostic biomarkers}

Studies to identify CSCs in cervical cancer frequently use experimental strategies that involve the sorting of tumor cell subpopulations, identification of surface markers and transplantation of these cells into the appropriate animal models (33). The surface markers CD133, CD34, CD44, CD26 and CD90 are used to identify and isolate CSCs from tumor cell populations. Additionally, these cells possess metastatic, invasive and chemoresistance abilities (10,34-37). Several potential cervical epithelial stem cell markers, including MSI1, ALDH1, SOX2 and CD49f, have been used to identify CCSCs $(10,15)$. In addition to MSI1, ALDH1, SOX2, CD49f and other markers, including CD44, CD133, CK-17 and Oct3/4, have also been used to identify CCSCs (10). The presence of this sub-population may help to predict the prognosis and chemoresistance of patients with cervical cancer. Additionally, CCSCs may be used as therapeutic targets for novel drugs that may increase the effectiveness of chemotherapy in patients with chemo-resistant forms of the disease.

Musashi-1. MSI1 is an RNA-binding protein expressed in the central nervous system. Mammalian MSI1 is a prominent marker of neural stem cells and progenitor cells, is expressed in several cancer types and has various cellular functions, including cell fate decision, maintenance of the stem-cell state and differentiation. It has also been reported to act as a positive regulator of cancer progression $(38,39)$. MSI1 is a translational regulator that has been demonstrated to be overexpressed in CCSCs (15). MSI1 expression is associated with the poor prognosis of patients with cervical squamous cell carcinoma, and is significantly correlated with CD49f expression, suggesting a functional role for these 2 proteins in cervical carcinogenesis (15). The expression of MSI1 may be used to predict the prognosis of patients with cervical cancer, thus personalized therapies directed at this protein may potentially be developed.

$A L D H 1$. ALDH1 is a detoxifying enzyme involved in the metabolism of endogenous and exogenous aldehydes, which reduces oxidative/electrophilic stress in prokaryotic and eukaryotic organisms (40). ALDH1 is involved in cellular differentiation, proliferation, mobility, embryonic development and organ homeostasis (41). ALDH expression is associated with higher rates of cell proliferation, sphere formation, migration and tumorigenesis in cervical cancer cells (42). It has also been reported that ALDH is associated with the chemo- and radio-resistance exhibited by CSCs (10). High expression of ALDH1 is associated with poor survival in patients with cervical squamous cell carcinoma that received postoperative adjuvant chemotherapy (15); as it was observed that ALDH1 expression predicts chemoresistance and poor clinical outcome in patients with cervical cancer, ALDH1 may also be a useful prognostic biomarker $(43,44)$. Furthermore, it was observed that knockdown of ALDH1 expression reduced the migrational ability of HeLa cells, whereas augmented expression of ALDH1 increased cell migration, indicating that ALDH1 is involved in cellular migration (45). It was also observed that CCSCs in cervosphere cultures possessed increased ALDH1 activity, which is, in turn, associated with higher tumorigenic activity (10). These results provide evidence of a link between ALDH1 expression, chemoresistance and poor clinical outcome in patients with cervical cancer.

Oct $3 / 4$. Oct $3 / 4$ is a transcription factor encoded by the POU domain class 5 transcription factor 1 gene that is involved in embryonic development, stem cell maintenance, tumor growth and metastasis $(46,47)$. Oct3/4 has been used as a biomarker of CSCs, though it cannot be used alone without considering other genes involved in the complex CSC phenotype, including Sox 2 , Nanog and ALDH1 $(23,48,49)$. Overexpression of Oct $3 / 4$ 


\section{HR-HPV}

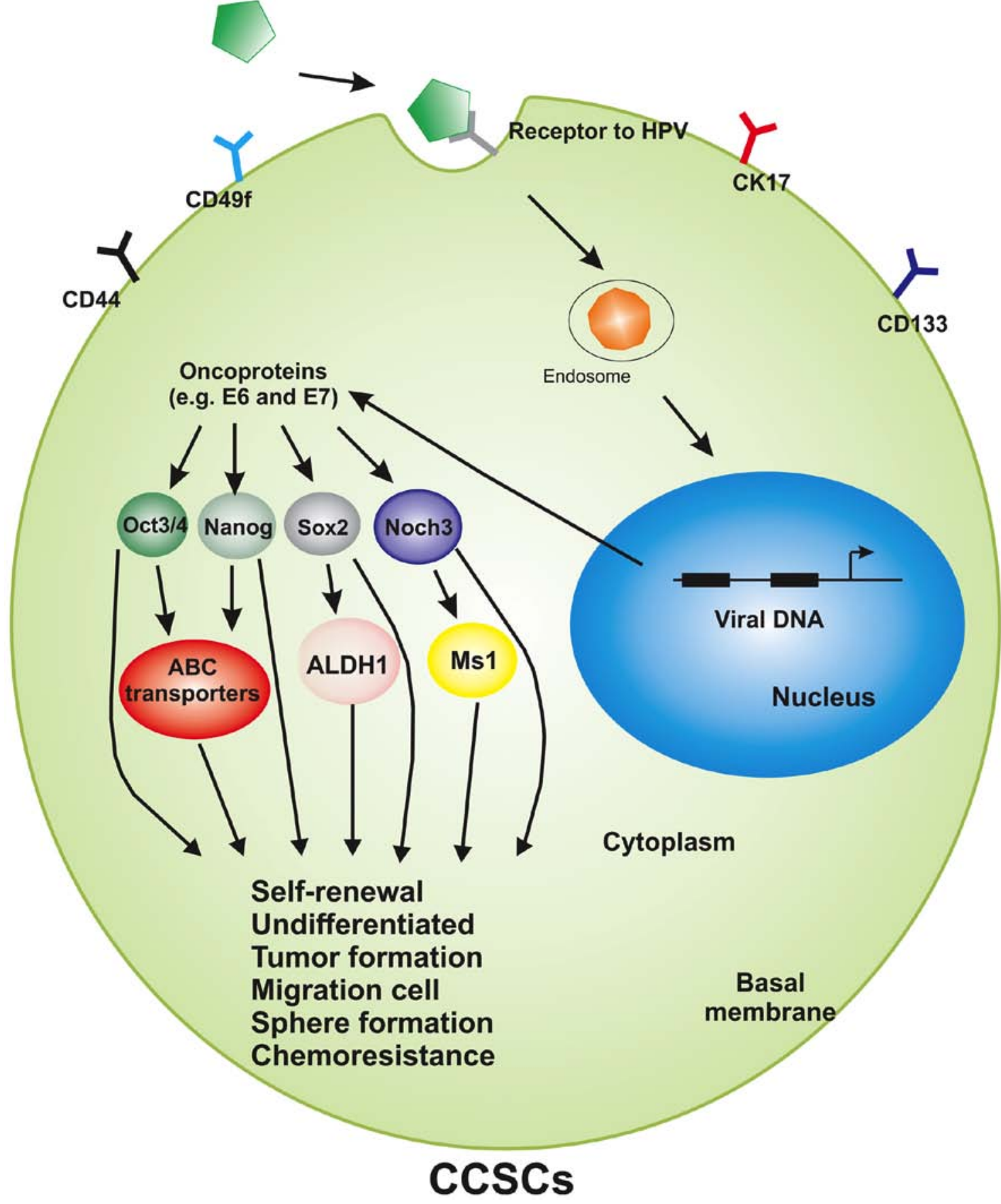

Figure 1. HR-HPV oncoprotein-mediated network regulation of CCSCs. HR-HPV targets stem cells of the cervical epithelium with the following surface markers: CD44, CD49f, CK17 and CD133. HR-HPV binds to receptors on the cell surface and the viral DNA is internalized and transported to the cell nucleus. Subsequently, the E6 and E7 oncogenes are transcribed and translated, giving rise to the oncoproteins E6 and E7. E6 and E7 have a number of molecular targets, including stemness-related genes Oct3/4, Nanog, Sox 2 and Notch3; overexpression of these genes promotes the formation of tumors, inhibits cancer cell apoptosis, cell migration and sphere formation. Oct $3 / 4$, Nanog. Sox 2 and Notch3 promote drug resistance via the upregulated expression of ABC transporters, ALDH1 and MSI1, which promotes the clonogenicity, proliferation, increased invasiveness and chemoresistance of CCSCs. HR-HPV, high risk-human papillomavirus; CCSCs, cervical cancer stem cells; ABC transporter, ATP-binding cassette transporter; ALDH1, aldehyde dehydrogenase 1; MSI1, Musashi-1.

has been used to determine its role in chemoresistance to multiple drugs. For example, transfection of Oct $3 / 4$ increases cisplatin resistance in cervical cancer cell lines (50). Although there have been limited studies on the association between Oct $3 / 4$ and the prognosis of patients with cervical cancer, Shen et al (51) reported that Oct $3 / 4$ expression was associated with radiation-resistance and poor survival in squamous cell carcinoma. Likewise, Yang et al (52) and Liu et al (53) demonstrated that Oct $3 / 4$ was highly expressed in CCSCs, is associated with biological behavior, and is a prognostic factor in cervical cancer. The expression of Oct $3 / 4$ in tumor cells is also associated with resistance to radiotherapy, which is an important predictor of poor survival in patients with cervical squamous cell carcinoma $(51,54)$. These results suggest that Oct $3 / 4$ expression is associated with poor prognosis in patients with cervical cancer. 


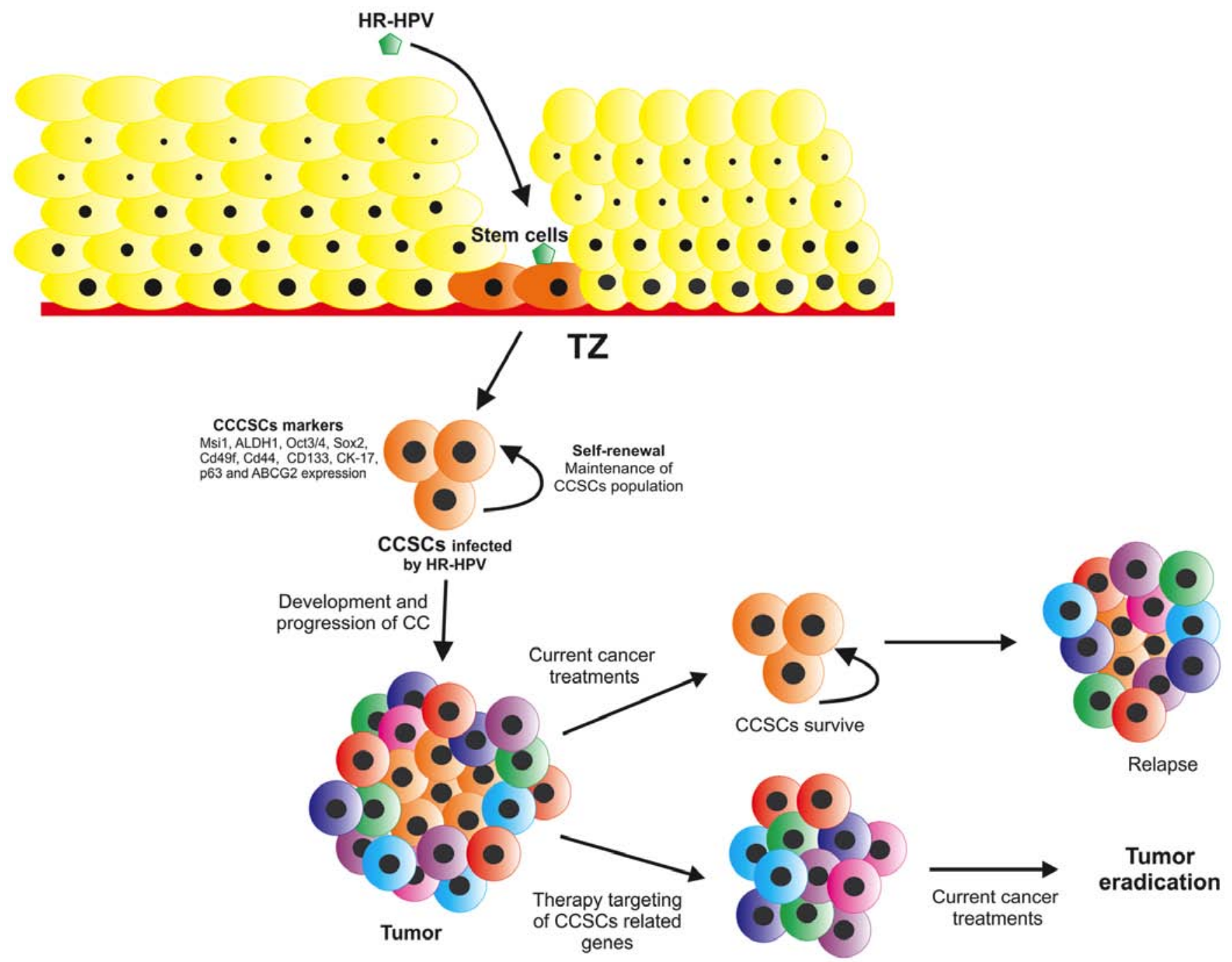

Figure 2. Model of the potential role of HR-HPV infection in CCSCs, and the implications for the treatment of cervical cancer. HR-HPV infects stem cells of the squamous epithelium, and HR-HPV oncoproteins HPV16 E6 and E7 are involved in the upregulation of Oct3/4, Sox2, Nanog and Fgf4 expression, which enhances the self-renewal and proliferation of cancer stem cells in cervical cancer. Current cancer treatments do not destroy CCSCs, leading to tumor recurrence and relapse. The combination of current cancer treatments with therapy directed at CCSC-associated genes may eradicate CCSCs, and tumor cells derived or transformed from CCSC. HR-HPV, high risk-human papillomavirus; CCSCs, cervical cancer stem cells.

Sox2. Sox2, a member of the SRY-related HMG-box family of transcription factors, serves a principal role in tissue development and cellular differentiation, and is associated with the stem cell phenotype. Sox 2 maintains stem cell-like properties in cancer cells by interacting with other stem cell markers, including Nanog and Oct3/4 $(25,55,56)$. The increased expression of Sox 2 has been observed in a variety of tumors; however, this is not a universal finding $(57,58)$. Sox 2 expression was reported to be higher in cervical cancer cells than in normal cervical cells. It was also observed to be strongly associated with poor prognosis in patients with cervical cancer $(15,51,58)$. Additionally, Sox 2-positive cells exhibit a greater capacity for self-renewal, differentiation and tumor formation $(29,59)$. Furthermore, Sox 2 overexpression is associated with poor survival and chemo-resistance $(51,58)$, suggesting that it may be a valuable prognostic biomarker in patients with cervical cancer.

CD49f. Integrin $\alpha 6$, also known as CD49f, is a biomarker commonly expressed in $>30$ different populations of stem cells, including certain CSC populations (60-62). CD49f has also been used for the characterization of CCSC populations from cervical cancer cell lines (HeLa, SiHa, Ca Ski and C-4 1). Additionally, CD49f-positive cells exhibit a greater capacity for self-renewal, enhanced tumorigenic capabilities and increased resistance to ionizing radiation, compared with CD49f-negative cells $(9,10)$. A high level of CD49f expression was also demonstrated in cervical tumor tissues, and is associated with the poor prognosis of patients with cervical cancer (15). Ammothumkandy et al (63) reported that $\mathrm{CD} 49 \mathrm{f}$ expression is associated with overall survival and progression in cervical cancer. Nevertheless, further investigation is required to gain a more complete understanding of the prognostic potential of CD49f expression in cervical cancer.

CD44. CD44 is a primary adhesion molecule expression in the extracellular matrix, and is involved in various biological processes. CD44 has been reported as a stem cell and CSC marker, and demonstrated to be involved in tumor progression 
and metastasis (64). Furthermore, CD44 expression in cervical cancer tissues was higher compared with that in normal, non-tumorous tissues (65). CD44-positive cells exhibit a greater capacity for self-renewal in subpopulations from various cervical cancer cell lines $(9,10)$, and CD44/CD24-positive cells exhibit radiation-resistance and possess stem cell characteristics (8); these studies suggest that CD44 expression has value as a predictive biomarker for radiation-resistance in patients with cervical cancer. Nevertheless, further research is required to confirm the prognostic significance of CD44 expression in cervical cancer.

CD133. CD133 is a glycoprotein with 5 transmembrane domains, that was initially identified in human hematopoietic stem cells (66). CD133 expression is not restricted to normal stem cells, as it has also been detected in tumors and used as a CSC biomarker (67). CD133-positive cells exhibit increased self-renewal properties, and proliferation and differentiation abilities $(67,68)$. Recently, it was reported that CD133-positive cells exhibited increased sphere-formation capacity compared with CD133-negative cells, providing further evidence to support its use as a biomarker of CCSCs. Additionally, high CD133 expression levels were detected in cervical carcinoma tissue biopsies (69), and CD133-positive CSCs were increased in radiation-resistant patients compared with those that were sensitive to radiotherapy; these data suggest that CD133 is a phenotypic marker of CSCs in cervical carcinoma (69), and that CD133 may be a prognostic biomarker in cervical cancer.

CK-17. CK17 is a keratinocyte marker and has been observed in the basal cells of the epithelium. It is also considered to be a biomarker for cervical stem cells and CSCs $(16,70)$. High expression of CK17 has been reported in patients with cervical cancer and is associated with the development of cervical lesions; it was also reported that CK17 expression is critical for maintaining stem cell properties $(10,16,17,71)$. Wu et al $(72)$ reported that the altered regulation of CK17 expression affects the initiation and tumor chemoresistance of cervical cancer, suggesting that CK17 may have value as a prognostic biomarker in patients with cervical cancer.

$A B C$ transporters. ABC transporters are one of the largest families of transmembrane proteins. These proteins use energy derived from ATP hydrolysis to transport numerous, chemically diverse compounds, including xenobiotics, antibiotics, toxins, vitamins, steroids, lipids, ions, polysaccharides, peptides and proteins, across the plasma membrane (73-75). However, these efflux mechanisms may protect cancer cells from first line cytotoxic drugs, and be responsible for resistance to chemotherapy. The most extensively characterized transporter within the ABC protein family is ATP-binding cassette sub-family B member 1 (ABCB1), which is associated with resistance to doxorubicin, paclitaxel and vincristine (75). ABCG2 is implicated in resistance to camptothecin analogues and mitoxantrone (76), and $\mathrm{ABCC} 1$ confers resistance to folate-based antimetabolites, anthracyclines, vinca-alkaloids and anti-androgens (77). ABC transporters are frequently overexpressed in CSCs $(73,74,78)$. As an efflux transporter on the cell membrane, ABCG2 has been reported to confer drug resistance by expelling chemotherapeutic agents out of cancer cells, and the increased expression of this transporter has been demonstrated in CCSCs $(53,79,80)$. These observations suggest that $\mathrm{ABC}$ transporters serve an important role in the maintenance of CCSCs and in chemo-resistance in cervical cancer.

On the other hand, it has been revealed that a number of compounds, including salinomycin $(81)$, curcumin $(82,83)$ and sulforaphane $(84,85)$, are not affected by resistance, and reduce tumor recurrence by destroying cancer cells and CSCs. Salinomycin, an antibiotic isolated from Streptomyces albus, has been shown to destroy CSCs in different types of human cancers, most likely by interfering with ABC drug transporters, the $\mathrm{Wnt} / \beta$-catenin signaling pathway and other pathways active in CSCs $(81,86)$. Due to its suppression of CSC-stimulating cytokines (including IL-6, -8 and -1) curcumin has numerous cytotoxic effects on CSCs, and effects on the Wnt, Notch, Hedgehog and focal adhesion kinase signaling pathways $(82,83)$. Sulforaphane also exhibits anticarcinogenic effects on CSCs, reducing proliferation and stimulating apoptosis of cancer cells, and interfering with numerous cell signaling pathways, including Keap1-Nrf2 signaling, the mitogen-activated protein kinase pathway and $\mathrm{NK}-\kappa \mathrm{B}$ signaling $(84,85)$.

\section{Conclusions}

Stem cells from the TZ of the cervical epithelium are targets for HR-HPV infection, which results in a unique expression profile that promotes the transformation of these cells into CCSCs (Fig. 1). CCSCs are involved in tumor development, metastasis, recurrence, resistance to multiple chemotherapeutic drugs and poor survival in patients with cervical cancer. Markers expressed by CCSCs include MSI1, ALDH1, Oct3/4, Sox2, CD49f, CD44, CD133, CK17 and ABC transporters. These biomarkers have potential to be used as prognostic indicators and therapeutic targets in patients with cervical cancer. Development of specific drugs and/or molecules to target CCSCs may provide the basis for an innovative treatment approach for the elimination of CSCs in cervical cancer (Fig. 1). Novel therapies based on the characteristics of CSCs, making them a target within the tumor, are crucial for improving clinical responses. Therefore, understanding the biology of CSC and the mechanism of CSC-targeted therapies may facilitate the development of effective treatments for patients with cervical cancer.

\section{Acknowledgements}

Not applicable.

\section{Funding}

The present study was supported by grant from CONACYT, México (Fondo Sectorial de Investigación en Salud y Seguridad Social; grant no. 201579).

\section{Availability of data and materials}

Not applicable. 


\section{Authors' contributions}

JON, YGG and OLGC collated the references and wrote this review. JON, MALV and BIA reviewed and edited the manuscript.

\section{Ethics approval and consent to participate}

Not applicable.

\section{Patient consent for publication}

Not applicable.

\section{Competing interests}

The authors declare that they have no competing interests.

\section{References}

1. Globocan 2012, Available at: http://globocan.iarc.fr. Accessed Oct, 2017.

2. Paavonen J: Human papillomavirus infection and the development of cervical cancer and related genital neoplasias. Int J Infect Dis 11 (Suppl 2): S3-S9, 2007.

3. Senapati R, Nayak B, Kar SK and Dwibedi B: HPV genotypes co-infections associated with cervical carcinoma: Special focus on phylogenetically related and non-vaccine targeted genotypes. PLoS One 12: e0187844, 2017.

4. Badaracco G, Savarese A, Micheli A, Rizzo C, Paolini F, Carosi M, Cutillo G, Vizza E, Arcangeli G and Venuti A: Persistence of HPV after radio-chemotherapy in locally advanced cervical cancer. Oncol Rep 23: 1093-1099, 2010.

5. Reya T, Morrison SJ, Clarke MF and Weissman IL: Stem cells, cancer, and cancer stem cells. Nature 414: 105-111, 2001.

6. Herfs M, Yamamoto Y, Laury A, Wang X, Nucci MR, McLaughlin-Drubin ME, Münger K, Feldman S, McKeon FD, Xian W and Crum CP: A discrete population of squamocolumnar junction cells implicated in the pathogenesis of cervical cancer. Proc Natl Acad Sci USA 109: 10516-10521, 2012.

7. Herfs M, Vargas SO, Yamamoto Y, Howitt BE, Nucci MR, Hornick JL, Mckeon FD, Xian W and Crum CP: A novel blueprint for 'top down' differentiation defines the cervical squamocolumnar junction during development, reproductive life, and neoplasia. J Pathol 229: 460-468, 2013.

8. Liu H, Wang YJ, Bian L, Fang ZH, Zhang QY and Cheng JX CD44+/CD24+ cervical cancer cells resist radiotherapy and exhibit properties of cancer stem cells. Eur Rev Med Pharmacol Sci 20: 1745-1754, 2016

9. López J, Poitevin A, Mendoza-Martínez V, Pérez-Plasencia C and García-Carrancá A: Cancer-initiating cells derived from established cervical cell lines exhibit stem-cell markers and increased radioresistance. BMC Cancer 12: 48, 2012.

10. Ortiz-Sánchez E, Santiago-López L, Cruz-Domínguez VB, Toledo-Guzmán ME, Hernández-Cueto D, Muñiz-Hernández S, Garrido E,De León DC and García-Carrancá A: Characterization of cervical cancer stem cell-like cells: Phenotyping, stemness, and human papilloma virus co-receptor expression. Oncotarget 7: 31943-31954, 2016.

11. Dobbin ZC and Landen CN: Isolation and characterization of potential cancer stem cells from solid human tumors-potential applications. Curr Protoc Pharmacol 63: Unit 14.28, 2013.

12. McLaughlin-Drubin ME, Meyers J and Munger K: Cancer associated human papillomaviruses. Curr Opin Virol 2: 459-466, 2012.

13. Organista-Nava J, Gómez-Gómez Y, Ocadiz-Delgado R, García-Villa E, Bonilla-Delgado J, Lagunas-Martínez A, Tapia JS, Lambert PF, García-Carrancá A and Gariglio P: The HPV16 E7 oncoprotein increases the expression of Oct3/4 and stemness-related genes and augments cell self-renewal. Virology 499: 230-242, 2016

14. Huang R and Rofstad EK: Cancer stem cells (CSCs), cervical CSCs and targeted therapies. Oncotarget 8: 35351-35367, 2017.
15. Hou T, Zhang W, Tong C, Kazobinka G, Huang X, Huang Y and Zhang Y: Putative stem cell markers in cervical squamous cell carcinoma are correlated with poor clinical outcome. BMC Cancer 15: 785, 2015.

16. Martens JE, Arends J, Van Der Linden PJ, De Boer BA and Helmerhorst TJ: Cytokeratin 17 and p63 are markers of the HPV target cell, the cervical stem cell. Anticancer Res 24: 771-776, 2004.

17. Ikeda K, Tate G, Suzuki T and Mitsuya T: Coordinate expression of cytokeratin 8 and cytokeratin 17 immunohistochemical staining in cervical intraepithelial neoplasia and cervical squamous cell carcinoma: An immunohistochemical analysis and review of the literature. Gynecol Oncol 108: 598-602, 2008.

18. Aksoy P, Gottschalk EY and Meneses PI: HPV entry into cells. Mutat Res Rev Mutat Res 772: 13-22, 2017.

19. López J, Ruíz G, Organista-Nava J, Gariglio $P$ and García-Carrancá A: Human papillomavirus infections and cancer stem cells of tumors from the uterine cervix. Open Virol J 6: 232-240, 2012

20. Olivero C, Lanfredini S, Borgogna C, Gariglio M and Patel GK: HPV-induced field cancerisation: Transformation of adult tissue stem cell into cancer stem cell. Front Microbiol 9: 546, 2018.

21. Kareta MS, Gorges LL, Hafeez S, Benayoun BA, Marro S, Zmoos AF, Cecchini MJ, Spacek D, Batista LF, O'Brien M, et al: Inhibition of pluripotency networks by the $\mathrm{Rb}$ tumor suppressor restricts reprogramming and tumorigenesis. Cell Stem Cell 16: 39-50, 2015.

22. Lin T, Chao C, Saito S, Mazur SJ, Murphy ME, Appella E and $\mathrm{Xu}$ Y: p53 induces differentiation of mouse embryonic stem cells by suppressing Nanog expression. Nat Cell Biol 7: 165-171, 2005.

23. Tyagi A, Vishnoi K, Mahata S, Verma G, Srivastava Y, Masaldan S, Roy BG, Bharti AC and Das BC: Cervical cancer stem cells selectively overexpress HPV oncoprotein E6 that controls stemness and self-renewal through upregulation of HES1. Clin Cancer Res 22: 4170-4184, 2016.

24. Xi R, Pan S, Chen X, Hui B, Zhang L, Fu S, Li X, Zhang X, Gong T, Guo J, et al: HPV16 E6-E7 induces cancer stem-like cells phenotypes in esophageal squamous cell carcinoma through the activation of PI3K/Akt signaling pathway in vitro and in vivo. Oncotarget 7: 57050-57065, 2016.

25. Liu K, Lin B, Zhao M, Yang X, Chen M, Gao A, Liu F, Que J and Lan X: The multiple roles for Sox 2 in stem cell maintenance and tumorigenesis. Cell Signal 25: 1264-1271, 2013.

26. Wang YD, Cai N, Wu XL, Cao HZ, Xie LL and Zheng PS: OCT4 promotes tumorigenesis and inhibits apoptosis of cervical cancer cells by miR-125b/BAK1 pathway. Cell Death Dis 4: e760, 2013

27. Ding Y, Yu AQ, Wang XL, Guo XR, Yuan YH and Li DS: Forced expression of Nanog with mRNA synthesized in vitro to evaluate the malignancy of HeLa cells through acquiring cancer stem cell phenotypes. Oncol Rep 35: 2643-2650, 2016.

28. Jeong JY, Kang H, Kim TH, Kim G, Heo JH, Kwon AY, Kim S Jung SG and An HJ: MicroRNA-136 inhibits cancer stem cell activity and enhances the anti-tumor effect of paclitaxel against chemoresistant ovarian cancer cells by targeting Notch3. Cancer Lett 386: 168-178, 2017.

29. Liu XF, Yang WT, Xu R, Liu JT and Zheng PS: Cervical cancer cells with positive Sox 2 expression exhibit the properties of cancer stem cells. PLoS One 9: e87092, 2014.

30. Yang L, Zhang X, Zhang M, Zhang J, Sheng Y, Sun X, Chen Q and Wang LX: Increased Nanog expression promotes tumor development and Cisplatin resistance in human esophageal cancer cells. Cell Physiol Biochem 30: 943-952, 2012.

31. Jia Q, Zhang X, Deng T and Gao J: Positive correlation of Oct4 and ABCG2 to chemotherapeutic resistance in CD90(+)CD133(+) liver cancer stem cells. Cell Reprogram 15: 143-150, 2013.

32. Pastò A, Serafin V, Pilotto G, Lago C, Bellio C, Trusolino L, Bertotti A, Hoey T, Plateroti M, Esposito G, et al: NOTCH3 signaling regulates MUSASHI-1 expression in metastatic colorectal cancer cells. Cancer Res 74: 2106-2118, 2014.

33. Feng D, Peng C, Li C, Zhou Y, Li M, Ling B, Wei H and Tian Z: Identification and characterization of cancer stem-like cells from primary carcinoma of the cervix uteri. Oncol Rep 22: 1129-1134, 2009.

34. Grasso C, Anaka M, Hofmann O, Sompallae R, Broadley K, Hide W, Berridge MV, Cebon J, Behren A and McConnell MJ: Iterative sorting reveals CD133+ and CD133-melanoma cells as phenotypically distinct populations. BMC Cancer 16: 726, 2016.

35. Wang P, Gao Q, Suo Z, Munthe E, Solberg S, Ma L, Wang M, Westerdaal NA, Kvalheim G and Gaudernack G: Identification and characterization of cells with cancer stem cell properties in human primary lung cancer cell lines. PLoS One 8: e57020, 2013. 
36. Muraro MG,Mele V,Däster S,Han J,Heberer M, Cesare Spagnoli G and Iezzi G: CD133+, CD166+CD44+, and CD24+CD44+ phenotypes fail to reliably identify cell populations with cancer stem cell functional features in established human colorectal cancer cell lines. Stem Cells Transl Med 1: 592-603, 2012.

37. Zakaria N, Yusoff NM, Zakaria Z, Lim MN, Baharuddin PJN, Fakiruddin KS and Yahaya B: Human non-small cell lung cancer expresses putative cancer stem cell markers and exhibits the transcriptomic profile of multipotent cells. BMC Cancer 15: 84, 2015

38. Chen HY, Lin LT, Wang ML, Tsai KL, Huang PI, Yang YP, Lee YY, Chen YW, Lo WL, Lan YT, et al: Musashi-1 promotes chemoresistant granule formation by PKR/eIF2 $\alpha$ signalling cascade in refractory glioblastoma. Biochim Biophys Acta Mol Basis Dis 1864: 1850-1861, 2018.

39. Okano $\mathrm{H}$, Imai $\mathrm{T}$ and Okabe M: Musashi: A translational regulator of cell fate. J Cell Sci 115: 1355-1359, 2002.

40. Singh S, Brocker C, Koppaka V, Chen Y, Jackson BC Matsumoto A, Thompson DC and Vasiliou V: Aldehyde dehydrogenases in cellular responses to oxidative/electrophilic stress. Free Radic Biol Med 56: 89-101, 2013.

41. Ueda K, Ogasawara S, Akiba J, Nakayama M, Todoroki K Ueda K, Sanada S, Suekane S, Noguchi M, Matsuoka K and Yano H: Aldehyde dehydrogenase 1 identifies cells with cancer stem cell-like properties in a human renal cell carcinoma cell line. PLoS One 8: e75463, 2013.

42. Rao QX, Yao TT, Zhang BZ, Lin RC, Chen ZL, Zhou H, Wang LJ, Lu HW, Chen Q, Di N and Lin ZQ: Expression and functional role of ALDH1 in cervical carcinoma cells. Asian Pac J Cancer Prev 13: 1325-1331, 2012

43. Xie Q, Liang J, Rao Q, Xie X, Li R, Liu Y, Zhou H, Han J, Yao T and Lin Z: Aldehyde dehydrogenase 1 expression predicts chemoresistance and poor clinical outcomes in patients with locally advanced cervical cancer treated with neoadjuvant chemotherapy prior to radical hysterectomy. Ann Surg Oncol 23: 163-170, 2016.

44. Yao T, Wu Z, Liu Y, Rao Q and Lin Z: Aldehyde dehydrogenase 1 (ALDH1) positivity correlates with poor prognosis in cervical cancer. J Int Med Res 42: 1038-1042, 2014.

45. Yao T, Lu R, Li Y, Peng Y, Ding M, Xie X and Lin Z: ALDH1 might influence the metastatic capability of HeLa cells. Tumor Biol 36: 7045-7051, 2015

46. Nichols J,Zevnik B, Anastassiadis K, Niwa H, Klewe-Nebenius D, Chambers I, Schöler H and Smith A: Formation of pluripotent stem cells in the mammalian embryo depends on the POU transcription factor Oct4. Cell 95: 379-391, 1998.

47. Loh YH, Wu Q, Chew JL, Vega VB, Zhang W, Chen X, Bourque G, George J, Leong B, Liu J, et al: The Oct4 and Nanog transcription network regulates pluripotency in mouse embryonic stem cells. Nat Genet 38: 431-440, 2006.

48. Yin X, Zhang BH, Zheng SS, Gao DM, Qiu SJ, Wu WZ and Ren ZG: Coexpression of gene Oct4 and Nanog initiates stem cell characteristics in hepatocellular carcinoma and promotes epithelial-mesenchymal transition through activation of Stat3/Snail signaling. J Hematol Oncol 8: 23, 2015.

49. Beier D, Hau P, Proescholdt M, Lohmeier A, Wischhusen J, Oefner PJ, Aigner L, Brawanski A, Bogdahn U and Beier CP CD133(+) and CD133(-) glioblastoma-derived cancer stem cells show differential growth characteristics and molecular profiles Cancer Res 67: 4010-4015, 2007.

50. Li SW, Wu XL, Dong CL, Xie XY, Wu JF and Zhang X: The differential expression of OCT4 isoforms in cervical carcinoma. PLoS One 10: e0118033, 2015

51. Shen L, Huang X, Xie X, Su J, Yuan J and Chen X: High expression of SOX2 and OCT4 indicates radiation resistance and an independent negative prognosis in cervical squamous cell carcinoma. J Histochem Cytochem 62: 499-509, 2014.

52. Yang Y, Wang Y, Yin C and Li X: Clinical significance of the stem cell gene Oct-4 in cervical cancer. Tumor Biol 35: 5339-5345, 2014

53. Liu H, Wang H, Li C, Zhang T, Meng X, Zhang Y and Qian H: Spheres from cervical cancer cells display stemness and cancer drug resistance. Oncol Lett 12: 2184-2188, 2016.

54. Villodre ES, Kipper FC, Pereira MB and Lenz G: Roles of OCT4 in tumorigenesis, cancer therapy resistance and prognosis. Cancer Treat Rev 51: 1-9, 2016.

55. Kim BW, Cho H, Choi CH, Ylaya K, Chung JY, Kim JH and Hewitt SM: Clinical significance of OCT4 and SOX2 protein expression in cervical cancer. BMC Cancer 15: 1015, 2015.

56. Boumahdi S, Driessens G, Lapouge G, Rorive S, Nassar D Le Mercier M, Delatte B, Caauwe A, Lenglez S, Nkusi E et al: SOX2 controls tumour initiation and cancer stem-cell functions in squamous-cell carcinoma. Nature 511: 246-250, 2014.
57. Wilbertz T, Wagner P, Petersen K, Stiedl AC, Scheble VJ, Maier S, Reischl M, Mikut R, Altorki NK, Moch H, et al: SOX2 gene amplification and protein overexpression are associated with better outcome in squamous cell lung cancer. Mod Pathol 24: 944-953, 2011.

58. Stewart CJ and Crook M: SOX2 expression in cervical intraepithelial neoplasia grade 3 (CIN3) and superficially invasive (stage IA1) squamous carcinoma of the cervix. Int J Gynecol Pathol 35: 566-573, 2016

59. Kaufhold S, Garbán H and Bonavida B: Yin Yang 1 is associated with cancer stem cell transcription factors (SOX2, OCT4, BMI1) and clinical implication. J Exp Clin Cancer Res 35: 84, 2016.

60. Krebsbach PH and Villa-Diaz LG: The role of integrin $\alpha 6$ (CD49f) in stem cells: More than a conserved biomarker. Stem Cells and Dev 26: 1090-1099, 2017.

61. Chang JY, Wang C, Jin C, Yang C, Huang Y, Liu J, McKeehan WL, D'Souza RN and Wang F: Self-renewal and multilineage differentiation of mouse dental epithelial stem cells. Stem Cell Res 11: 990-1002, 2013

62. Villanueva-Toledo J, Ponciano-Gómez A, Ortiz-Sánchez E and Garrido E: Side populations from cervical-cancer-derived cell lines have stem-cell-like properties. Mol Biol Rep 41: 1993-2004, 2014.

63. Ammothumkandy A, Maliekal TT, Bose MV, Rajkumar T, Shirley S, Thejaswini B, Giri VG and Krishna S: CD66 and CD49f expressing cells are associated with distinct neoplastic phenotypes and progression in human cervical cancer. Eur J Cancer 60: 166-178, 2016.

64. Castelli G, Pelosi E and Testa U: Liver cancer: Molecular characterization, clonal evolution and cancer stem cells. Cancers (Basel) 9: pii: E127, 2017.

65. Xiao S, Zhou Y, Jiang J, Yuan L and Xue M: CD44 affects the expression level of FOS-like antigen 1 in cervical cancer tissues. Mol Med Rep 9: 1667-1674, 2014.

66. Yin AH, Miraglia S, Zanjani ED, Almeida-Porada G, Ogawa M, Leary AG, Olweus J, Kearney J and Buck DW: AC133, a novel marker for human hematopoietic stem and progenitor cells. Blood 90: 5002-5012, 1997.

67. Jang JW, Song Y,Kim SH,Kim J and Seo HR: Potential mechanisms of CD133 in cancer stem cells. Life Sci 184: 25-29, 2017.

68. Singh SK, Hawkins C, Clarke ID, Squire JA, Bayani J, Hide T, Henkelman RM, Cusimano MD and Dirks PB: Identification of human brain tumour initiating cells. Nature 432: 396-401, 2004.

69. Javed S, Sharma BK, Sood S, Sharma S, Bagga R, Bhattacharyya S, Rayat CS, Dhaliwal L and Srinivasan R: Significance of CD133 positive cells in four novel HPV-16 positive cervical cancer-derived cell lines and biopsies of invasive cervical cancer. BMC Cancer 18: 357, 2018.

70. McGowan KM and Coulombe PA: Onset of keratin 17 expression coincides with the definition of major epithelial lineages during skin development. J Cell Biol 143: 469-486, 1998.

71. Carrilho C, Alberto M, Buane L and David L: Keratins 8, 10 , 13 , and 17 are useful markers in the diagnosis of human cervix carcinomas. Hum Pathol 35: 546-551, 2004

72. Wu L, Han L, Zhou C, Wei W, Chen X, Yi H, Wu X, Bai X, Guo S, Yu Y, et al: TGF- $\beta 1$-induced CK17 enhances cancer stem cell-like properties rather than EMT in promoting cervical cancer metastasis via the ERK1/2-MZF1 signaling pathway. FEBS J 284: 3000-3017, 2017.

73. Thomas $\mathrm{C}$ and Tampé R: Multifaceted structures and mechanisms of $\mathrm{ABC}$ transport systems in health and disease. Curr Opin Struct Biol 51: 116-128, 2018.

74. Begicevic RR and Falasca M: ABC transporters in cancer stem cells: Beyond chemoresistance. Int J Mol Sci 18: pii: E2362, 2017.

75. Shukla S, Ohnuma S and Ambudkar SV: Improving cancer chemotherapy with modulators of ABC drug transporters. Curr Drug Targets 12: 621-630, 2011.

76. Noguchi K, Katayama K and Sugimoto Y: Human ABC transporter ABCG2/BCRP expression in chemoresistance: Basic and clinical perspectives for molecular cancer therapeutics. Pharmgenomics Pers Med 7: 53-64, 2014.

77. Dębska S, Owecka A, Czernek U, Szydłowska-Pazera K, Habib M and Potemski P: Transmembrane transporters ABCC-structure, function and role in multidrug resistance of cancer cells. Postepy Hig Med Dosw (Online) 65: 552-561, 2011 (In Polish).

78. Kim JK, Jeon HY and Kim H: The molecular mechanisms underlying the therapeutic resistance of cancer stem cells. Arch Pharm Res 38: 389-401, 2015.

79. Tyagi A, Vishnoi K, Kaur H, Srivastava Y, Roy BG, Das BC and Bharti AC: Cervical cancer stem cells manifest radioresistance: Association with upregulated AP-1 activity. Sci Rep 7: 4781, 2017. 
80. Wei ZT, Yu XW, He JX, Liu Y and Zhang SL: Characteristics of primary side population cervical cancer cells. Oncol Lett 14: 3536-3544, 2017.

81. Zhang Y, Liu L, Li F, Wu T, Jiang H, Jiang X, Du X and Wang Y: Salinomycin exerts anticancer effects on PC-3 cells and PC-3-derived cancer stem cells in vitro and in vivo. Biomed Res Int 2017: 4101653, 2017.

82. Sordillo PP and Helson L: Curcumin and cancer stem cells: Curcumin has asymmetrical effects on cancer and normal stem cells. Anticancer Res 35: 599-614, 2015.

83. Li Y and Zhang T: Targeting cancer stem cells by curcumin and clinical applications. Cancer Lett 346: 197-205, 2014.

84. Liu CM, Peng CY, Liao YW, Lu MY, Tsai ML, Yeh JC, Yu CH and Yu CC: Sulforaphane targets cancer stemness and tumor initiating properties in oral squamous cell carcinomas via miR-200c induction. J Formos Med Assoc 116: 41-48, 2017.
85. Wang X, Li Y, Dai Y, Liu Q, Ning S, Liu J, Shen Z, Zhu D, Jiang F and Li Z: Sulforaphane improves chemotherapy efficacy by targeting cancer stem cell-like properties via the miR-124/IL-6R/STAT3 axis. Sci Rep 6: 36796, 2016.

86. Naujokat $C$ and Steinhart $R$ : Salinomycin as a drug for targeting human cancer stem cells. J Biomed Biotechnol 2012: 950658 , 2012.

This work is licensed under a Creative Commons Attribution-NonCommercial-NoDerivatives 4.0 International (CC BY-NC-ND 4.0) License. 